\title{
Virtual Reality (VR) Safety Education for Ship Engine Training on Maintenance and Safety (ShipSEVR)
}

\author{
Evangelos Markopoulos ${ }^{1,2}$, Mika Luimula ${ }^{2}$, Pasi Porramo ${ }^{3}$, Tayfun Pisirici ${ }^{4}$, Aleksi \\ Kirjonen $^{4}$ \\ ${ }^{1}$ University College London, School of Management, Gower St, Bloomsbury, WC1E 6BT, \\ London, United Kingdom \\ ${ }^{2}$ Turku University of Applied Sciences. Faculty of Engineering and Business Joukahaisen- \\ katu 3, ICT-City, C-wing, FI-20520 Turku, Finland \\ ${ }_{3}^{3}$ Ade Ltd, 144 Hämeen Valtatie, 2054034, Turku, Finland \\ ${ }^{4}$ Wärtsilä Land and Sea Academy, Stålarminkatu 45, 20810 Turku, Finland \\ e.markopoulos@ucl.ac.uk,mika.luimula@turkuamk.fi,pasi@ade.fi, tayfun.pisirici@wart- \\ sila.com, aleksi.kirjonen@wartsila.com
}

\begin{abstract}
The training and educational skills expected today from maritime engineers surpass their ability to follow them consistently. Such knowledge gap can impact significantly ship safety and operations. On this reality, ship engineers face multiple challenges related with the time required to be educated on each engine type, time needed to spend off the ship to acquire this training, the continuous training cost, and the easy access to complete engineering documentation and schematics. This paper attempts resolve these challenges with ShipSEVR (Ship Safety Education with Virtual Reality). The technology delivered has been achieved with the contribution of the smart technology company Wärtsilä and Ade with the contribution of VR development. TUAS, Ade, and Wärtsilä work close on research to optimize this engine room virtual reality training environment and impact ship and maritime safety. The paper demonstrates the industry challenge, technology architecture, working prototype, implementation methods, and adaptation techniques.
\end{abstract}

Keywords: Virtual Reality · Game Design $\cdot$ Engine Room $\cdot$ Engine $\cdot$ Maritime $\cdot$ Ship $\cdot$ Safety $\cdot$ Management $\cdot$ Technology $\cdot$ Learning Environment $\cdot$ Wärtsilä

\section{Introduction}

The continuous growth of the maritime industry along with the advancements of engineering creates a tremendous technical complexity on operating and maintaining engines and engine rooms safely and effectively. Lack of training time and training costs are critical factors that impact safety in the engine rooms. Due to the nature of maritime, it is challenging to facilitate training which would require both classroom and field work activities. To achieve or maintain professional level of engineering skills requires abilities to utilize engineering documentation just in time efficiently. Even that safety cannot be categorized by the degree of industry importance or areas of application, there are specific sectors, such as the maritime, where the need for absolute effective safety 
procedures must be followed precisely either proactively, or even reactively. A vessel sailing in the middle of an ocean is totality on its own when an accident happens. The response time for help to be provided can be unpredictable as the vessel might not be able approachable, or the help might be insufficient. According to the Japan Transport and Safety Board, 199 marine incident cases were recorded from January $1^{\text {st }}$ to November $30^{\text {th }} 2019$ (Fig. 1). From those, 84\%, or 167, were due to engineering and engine room incidents such as machinery and propulsion failure, or insufficient fuel, lube, oil or cooling water [1].

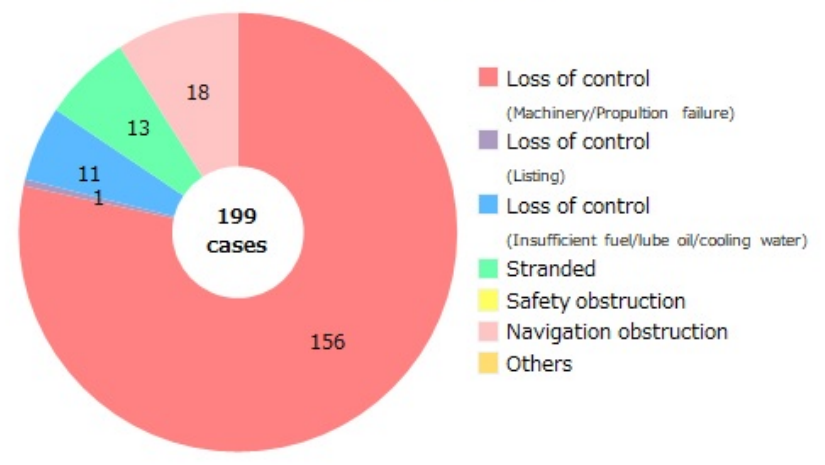

Fig. 1. Number of Marine Incidents in 2019 [1]

Similarly, the Maritime Injury Guide indicates that equipment failure, lack of maintenance, lack of proper training / human error and collisions are the three main categories of maritime accidents [2]. Specifically, lack of constant and proper maintenance for equipment failure prevention, failure to monitor a ship's systems and lack of the necessary protective parts or equipment are among the major factors that contribute to maritime accidents.

\section{$2 \quad$ On-Ship Safety Training}

The maritime industry is one with many dangers and risks as accidents and injuries can happen out of nowhere, leaving behind devastating results. Accidents don't pick sides when they happen. It can be the ship owners' fault for not providing proper tools and training to the crew but also the crew's fault for not keeping up with needed training. Both cases have the cost as common denominators. Effective and professional training is a significant cost for the shipping companies and requires substantial time and effort from the crew to go through it successfully. However, there is one more factor that contributes to the poor or lack of maritime training and this is the time period a ship can lose for the completion of a training program. This impacts the operations costs of the shipping company as the more a ship is on the move the more profit it makes. Therefore, the need to move to on-board training is important and critical [3].

As of today, the on-board training is delivered mainly with either on-line courses or physical training in classrooms or in designated work areas. The first type has limited 
effectiveness as the seafarers study on their own while the second type cannot be delivered on all ships and can be very expensive if all the training costs are counted (Planning, Programme development and design, Delivery and Evaluation) [4].

\section{$3 \quad$ Futuristic Technologies on Ship Safety Training}

The transition from the on-shore training to the on-board training in the maritime sector is not only a need but also a new area of application for advanced and futuristic technologies [5]. The maritime sector has been considered quite conservative to keep up with the technology needed to implement such solutions [6] but this change is happening, and the technology is quite tempting and cannot be ignored.

On board training can be achieved with the use of Artificial intelligence (AI) expert systems, decision support systems, blockchain technology and machine learning. AI constantly transforms data into knowledge and knowledge into expertise. Orca AI systems develops AI-backed navigation tools for the maritime industry to help prevent costly collisions [7]. The technology works with thermal and low light cameras, onboard sensors and an AI-powered vessel tracking and navigation system through which the crew can avoid collision by ship detection. Gamification has been also being used in maritime training as the technology contributes much beyond training. Gamified training provides information on the ways a game is played. This generates information from the player's habits, behaviors, signs, images, sounds, gestures, etc., while a game is played, based on the way the contents is structured and delivered [8].

Virtual Reality, on the other hand, extends the maritime simulation-based training by bringing the simulation through the VR glasses to wherever the trainee is. Virtual Reality reduces the time and cost needed for simulation-based training while increases the accessibility and opportunity to on-board maritime training [9]. MarSEVR is a technology developed at TUAS to handle unlimited maritime safety applications and scenarios. The first MarSEVR application was a decision making and situation awareness case by replicating a ship bridge environment and creating various training scenarios in a close cooperation with maritime specialist from Aboa Mare with difficulty levels. The application emphasizes on watch change between two navigation officers on a cargo ships bridge and on the events that happen after the watch change [10].

Lastly holograms seem to enter the maritime industry as well. The Japanese maritime services company, JRCS, imagines the future of maritime to be with self-navigating ships and digital captains. This can be achieved with the use of mixed reality, artificial intelligence and holograms [11]. While developing MarSEVR and now ShipSEVR one of our intention is to design a learning environment which can be integrated later in remote controlled and at the end when autonomous vessels are reality remote monitored systems as an advanced user interface.

\section{The ShipSEVR Project}

In an attempt to keep up with the maritime technology trends, research was conducted to examine and develop ShipSEVR (Ship Engine Safety Education Virtual Reality), a VR Training next generation learning environment focused specifically on ship engines 
and engine rooms safety procedures. The technology has been designed and developed at AVR Turku Innovation and Competence Factory (AVR Turku) for Wärtsilä Land and Sea Academy (WLSA) utilizing latest VR technologies. AVR Turku is a joint innovation environment owned by TUAS where researchers, students and companies are working closely together. In this project, TUAS and its industrial partners Wärtsilä and Ade focus on VR development utilizing successfully the AVR Turku innovation strategy by starting the innovation process with students and researchers and finishing it with the commercialization of the first ShipSEVR learning episode.

The delivered learning episode consists of a 3D ship engine room space where trainees are expected to find certain devices and equipment by utilizing the available technical drawings. The technology was tested intensively by WLSA at their Turku premises and the promising results helped the project continue.

The development process had been split in three phases, (a) reviewing the state-ofthe-art solutions globally, (b) prototyping with teams five students latest UI solutions from the gaming industry, and (c) finalizing the first commercial training episode. The reviewing phase conducted in early 2018 revealed some bottlenecks current VR training solutions typically have especially in usability, and user experience.

The initial research team, composed from five ICT students studying game technology at TUAS, was involved in autumn 2018 and worked with unique system check lists provided by Wärtsilä LSA. Their work was coached by TUAS academics, lecturers and engineers in a close cooperation with VR specialists from Ade Ltd. Wärtsilä LSA training specialists were frequently involved to provide valuable feedback and receive ideas from gaming engineers on how state-of-the-art in VR gaming could be utilized outside the gaming industry and particularly in shipping, where users are not experienced gamers but maritime engineers with limited computer skills.

\section{The ShipSEVR Research Process}

This project became part of the TUAS Advanced Game Technologies course in autumn 2018. Wärtsilä shared one 3D model of Wärtsilä LNG-carrier ship design (Fig. 2.) through ftp server, and documentation for five system check lists on Fuel System, Cooling System, Lubricating Oil System, and Start Air System, and Exhaust Gas.

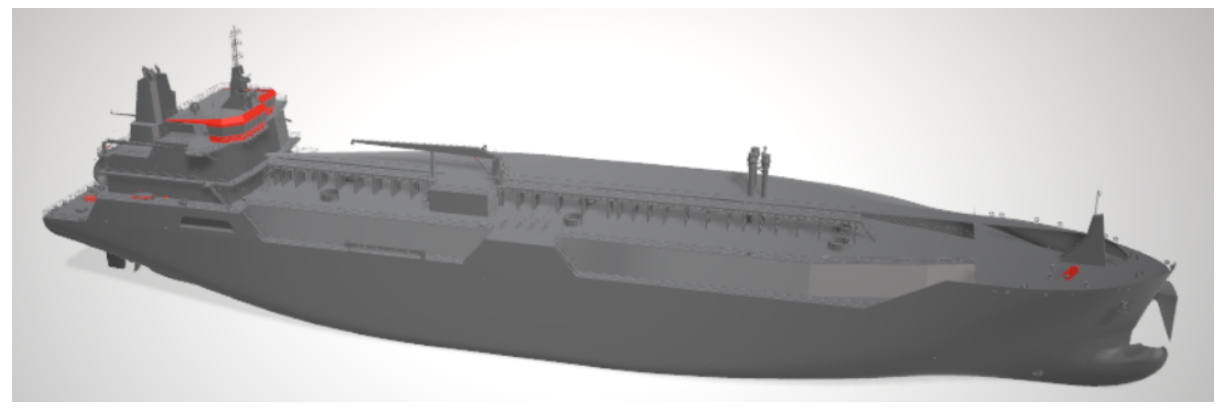

Fig. 2. Wärtsilä LNG-carrier 3D ship design

Each check list was supported with the relevant documentation and technical diagrams. 
The research students worked in groups on the checklists under specific instructions and challenges. For example, the group that focused on Cooling Water System received commissioning instructions for checking for all engine and auxiliary equipment connections, leaks on running pumps, and the position of a HT thermostatic valve. They were supported with the diagram of the external cooling water system for in-line engines (Fig. 3), with photos of an installation and with general training slides that have been used in traditional marine commissioning trainings.

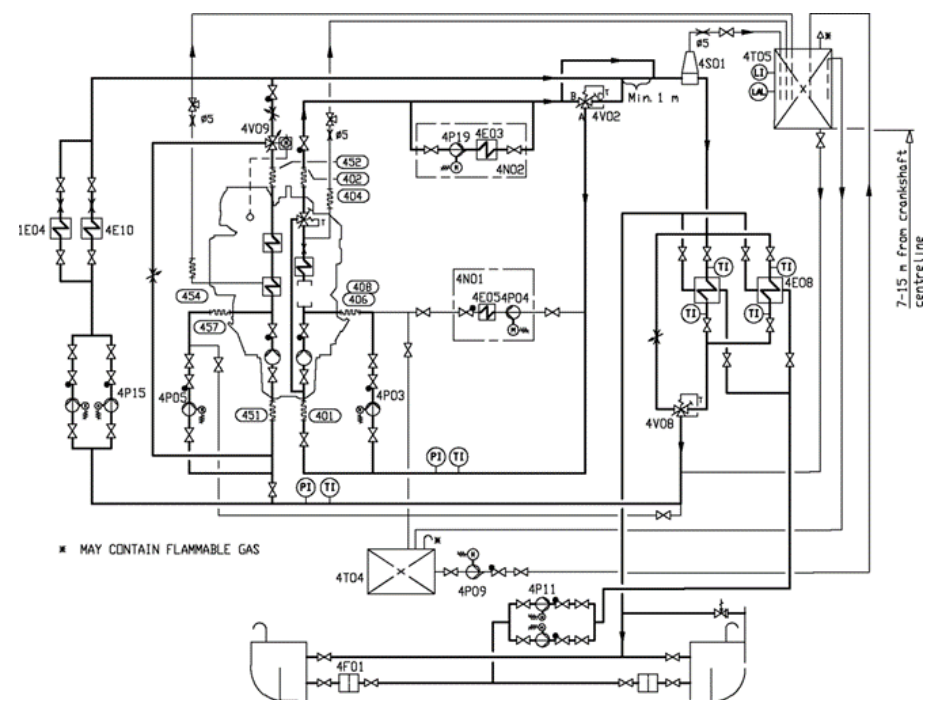

Fig. 3. External cooling water system, in-line engines

However even that 3D design of these types of systems are available, challenges in usability, user experience and complex user interface designs have made the usability of these 3D assets very complex and less insufficient for training purposes.

Through this project Wärtsilä aimed to explore the kind of innovations game developers could bring on board due to their gaming background. The game industry, through serious games, can tackle the challenges Wärtsilä had in usability, user experience, and UI design. In order to achieve better results Wärtsilä provided a detailed 3D model of Wärtsilä 34DF engine generating set (Fig. 4) which got integrated in the technology.

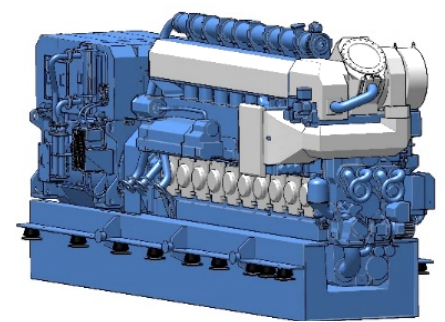

Fig. 4. 3D Model of Wärtsilä 34DF engine generating set 


\section{Initial demo results of ShipSEVR}

The first deliverables and demos of the technology from this research were presented in November 2019 as first demos in the Allied ICT Finland seminar in Aboa Mare maritime academy and training center receiving significant and constructive feedback. The Cooling Water System team developed a well-designed VR tutorial to tackle usability and user experience challenges (Fig. 5). This was an important Wärtsilä requirement. The tutorial was located at the entrance of the ship engine room. The interaction methods and the UI were explained in detail to the users before entering the room (Fig. 6).
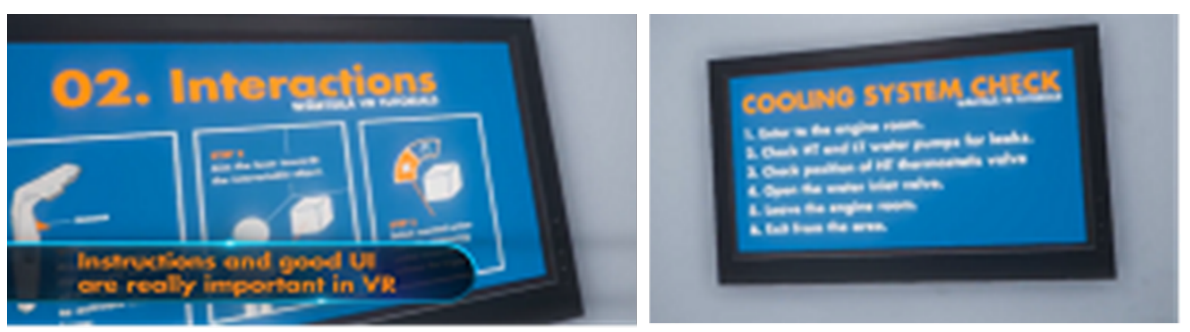

Fig. 5. VR Tutorial

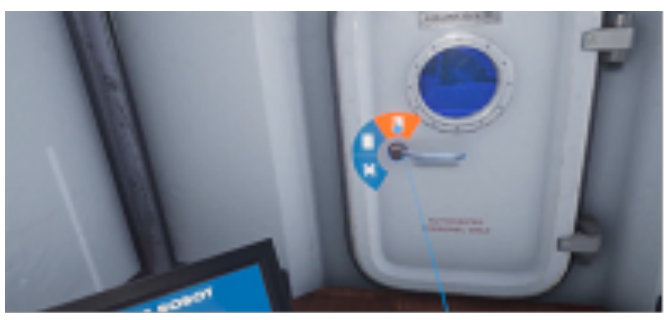

Fig. 6. Engine Room Entrance with the tutorial infront of it

To increase the easiness, a virtual robot guide was invented to instruct the users during the training session. In practice, instructions of the task and the content of the system check list were available when ever needed (Fig. 7).
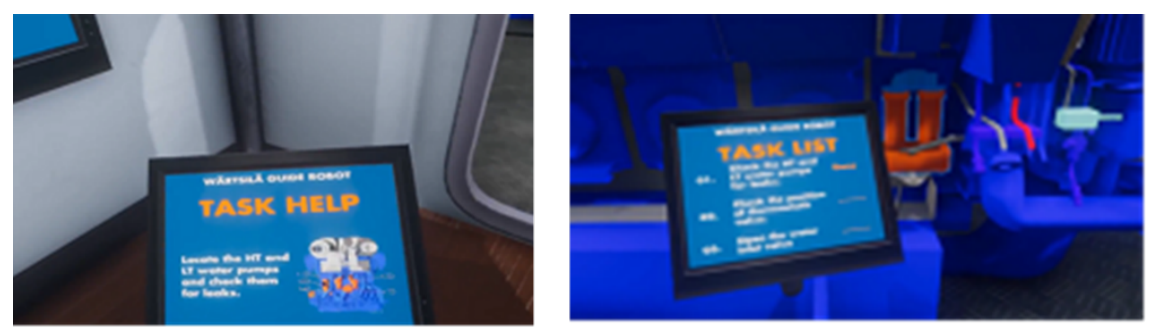
Fig. 7. Cooling Water System Instructions and Task List.

To avoid any misunderstandings, feedback was given just in time. The feedback including highlighting of the active objects by utilizing both informative UI menu elements and concrete animations (Fig. 8).
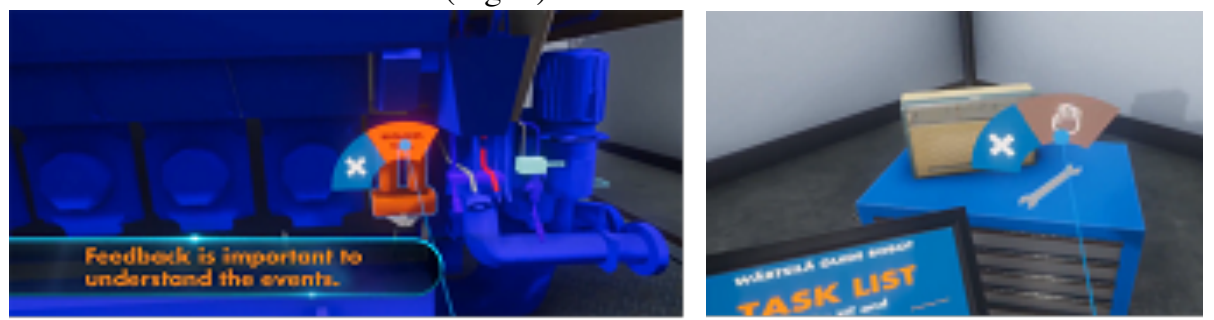

Fig. 8. Animated Feedback.

\section{Results and ShipSERV Commercialization}

The first complete version of the ShipSEVR Technology was completed on December 2018 with the final presentation tasking place at the TUAS Labs with the participation of Wärtsilä's and Ade's representatives. The results were impressive, Wärtsilä was quite satisfied and decided to apply innovative gaming elements of five student groups in a commercial version.

This commercialization phase started early January 2019. Engineers from TUAS together with Ade's VR specialists worked together in a close cooperation with Wärtsilä for the enhanced version of the technology. In addition to the system check lists, ShipSEVR now includes an extra application at the introduction phase before starting the actual training system checks. This VR solution uses the "exact" ship's 3D model of Wärtsilä's WSD Platform Supply Vessel designed by Ship Design unit at the Stord office in Norway (Fig. 9)
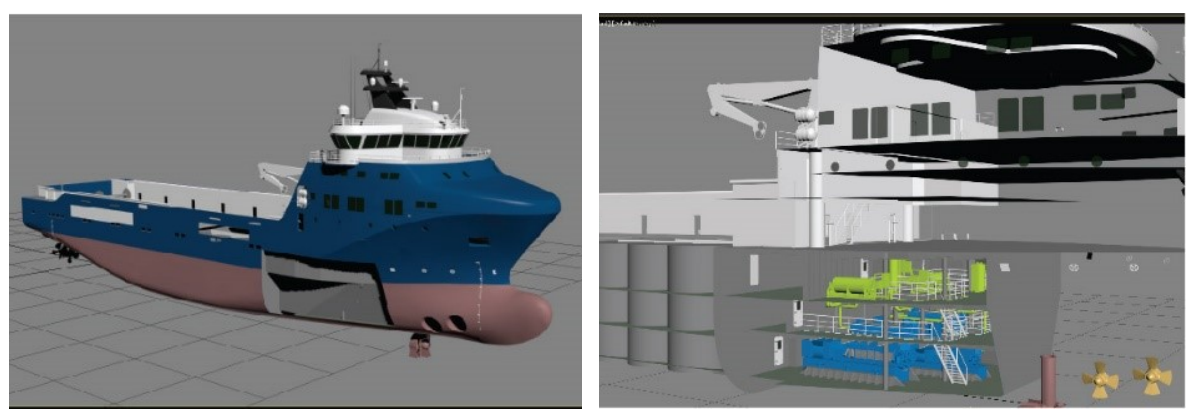

Fig. 9. 3D model of Wärtsilä’s WSD Platform Supply Vessel

Ship Technical specifications: Length: over all $92.50 \mathrm{~m}$, Deadweight: 5900 tonnes, Deck area: 1090 m2, Speed: 14.7 knots, ERN: 99.99.99.9 
Design highlights: Dual Fuel. LNG/MDO, DP, ERN 99.99.99.99 Compact high capacity cargo area

In ShipSEVR, the ship was equipped with following main generator sets (Fig. 10):

2 x Wärtsilä 6L20DF $1014 \mathrm{~kW}$ and 2 x Wärtsilä 6L34DF $2510 \mathrm{~kW}$. Thus, it is a Diesel-electric propulsion (running mainly on gas) with Wärtsilä LNGPac, engine specific gas valve units (GVU) and engine auxiliary equipment.
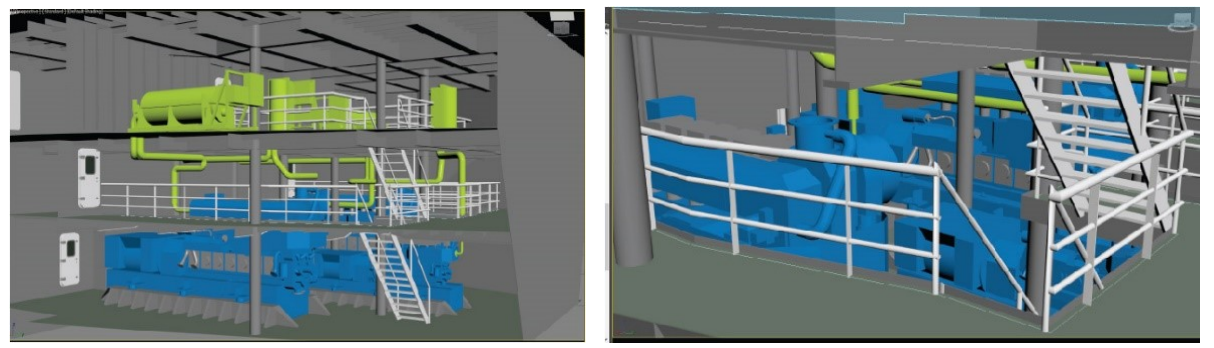

Fig. 10. 3D models of ShipSEVR, ship generator sets

The generator models helped ShipSEVR to develop a realistic virtual environment of the ship's engine and engine room. The user is able to move freely around the engine room by using teleport moving system (Fig. 11).
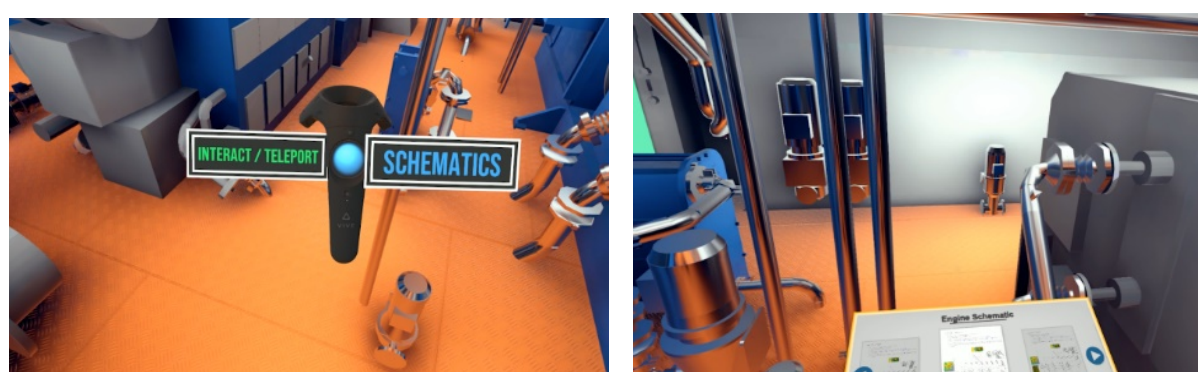

Fig. 11. Engine and Engine room teleport navigation

During the tests, the users were asked to find certain devices by using real, detailed and office engine schematics documentation from Wärtsilä (Fig. 12). This solution is designed for engineers but can also be used in TUAS engineering education. For engineers, this solution brings just in time all required documentation visually and easily available. This approach is totally unique 1) compared to traditional way of learning first in classroom without understanding of real-world challenges and context and 2) compared to field work training where especially novices have challenges to read and understand documentation efficiently in harsh ship engine room conditions.

Consequently, at the end of this commercialization phase, TUAS and Ade provided a solution where trainees can open easily all engine schematics whenever needed. In practice, schematics could be browsed by using VR controllers' trackpad buttons (left/right). In addition, these schematics could be zoomed in / out. 


\section{$8 \quad$ VR extends Training and Education to Behavioral Analysis}

ShipSEVR extends to a very important factor in training, often neglected, which is the utilization of data analytics related to the trainee behavior during one or more training sessions. When such data are not collected training remains at formal educational goals, in which knowledge and skills are transmitted to the trainee. However, the use of technology can provide behavioral and psychology analysis of the trainee. Virtual reality is a powerful tool for human behavior research. The ability the technology offers to create $3 \mathrm{D}$ visual scenes and to measure the responses to the visual stimuli, allows behavioral researchers to test hypotheses in a manner and scale unfeasible previously [12]

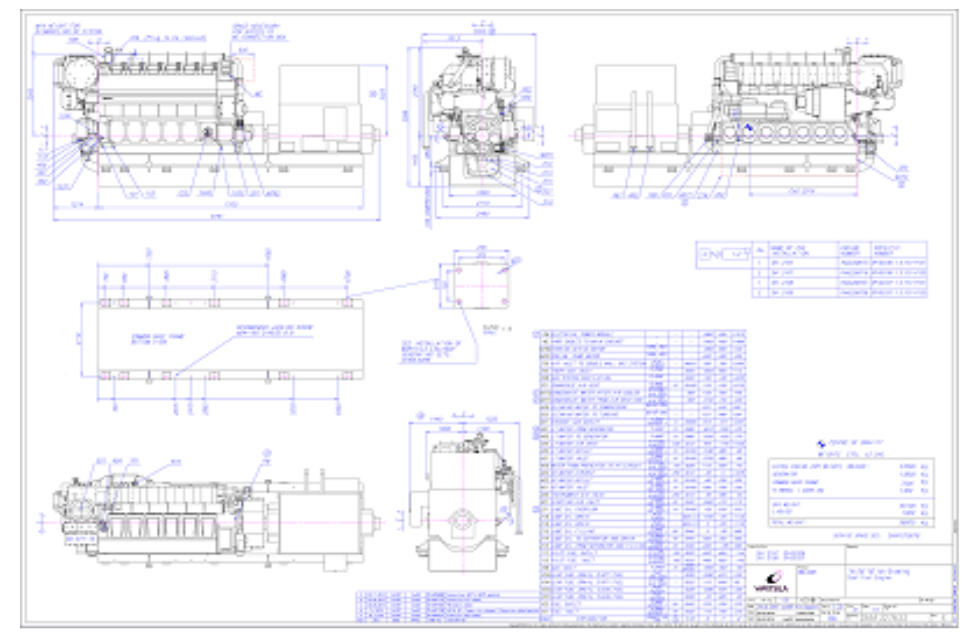

Fig. 12. Engine installation drawing

VR provides a unique advantage for such analysis as the eyes of the trainee are recorded and tracked at every instance. Hardware wise, ShipSEVR intends to integrate one of the most promising new VR technologies which is the Varjo's VR-1 glasses with human-eye resolution. This type of glasses can offer, especially in maritime, opportunities to focus on solutions where detailed textual or other visual information is a crucial part of learning aspects in maritime education. Also Leap Motion and other finger recognition technologies will offer not only better usability experiences but also provide new tools for analyzing trainees' behavior. If for example the trainees hesitate between making a choice on how to approach a machine, what tool to use or what metric instrument to consult, these thoughts are recoded and identified with sight traction. Staring at a wrong tool for example is a mistake even if the trainee does not decide to use the wrong tool and finally select the right one. The time to response can also measure by the time the sight of the trainee remains still, at the wrong place, or is lost in the environment.

The combination of such behavioral metrics can be analyzed to identify the readiness and the emotional and the psychological status of the trainee at the time of emergency situations or at routine maintenance work in the engine room. 


\section{ShipSEVR Impact on the Shipping Industry}

ShipSEVR was developed as a research project to identify the degree of safety training effectiveness in engine rooms and its impact to the shipping industry. As the shipping industry indicates high rotation on the on-board crew, the need for continuous training on the new crew to obtain the needed engagement towards achieving safety performance is critical and important [13]. However, the ability to deliver physical and hands on training on the engines and inside the engine rooms while a ship sails is not only possible but also very dangerous.

ShipSEVR can transform any location on the ship, even a cabin, into a virtual space with a precise simulation of the real engine room conditions, space layout and engines. The technology provides accessibility to engine and engineer room schematics, technical diagrams and documentation at the trainee eyes, as a portable digital technical library. The easiness to access, read, analyze the details (zooming), search and store technical documentation is a significant contribution to shipping engine maintenance as most of the physical technical documentation is not easily accessible when needed and not in good conditions due to their usage. Unlimited training scenarios can be delivered in ShipSEVR as various challenges can be combined on type of work to delivered, physical challenges in the engine room and emergency or critical situations.

ShipSEVR was developed for safety training and education in engine rooms but its operations aims to extend the safety scope with the integration of behavioral analytics that predict not only the ability of the engineer to perform safety operations effectively but also on recognizing the emotional and physical state of the engineer to deliver a technical safety challenge.

Transforming this functionality and contribution into financial terms the benefits for both the shipping companies, the shipyards and the engine manufacturers are highly considerable in both financial and reputational costs. The effectives of ShipSEVR reduces the training costs, identifies capable crew to trust the engine room, reduces the possibility to have any type of accident, increases the safety standards and practices, and ranks rewardingly the well-trained crew though its pontification system.

Furthermore, ShipSEVR increases the shipping companies reputation for their efficient and safe operations but also the engine manufactures' reputation for their adaptation and alignment with advances technologies as supportive tools to their customers.

\section{Areas of Further Research}

The development on ShipSEVR is expected to continue towards the integration of behavioral and cognitive science technologies.

The research will be directed on the identification and the development of user response metrics that will be scored based on the readiness, the behavior and the correct answers given, or acts executed.

The technology intends to prioritize each engine room challenge based on its criticality and complexity, and to provides response time intervals and accepted angels of view, as behavioral characteristics that can indicate the concentration of the trainee and the practical deliver of the knowledge gained in the theoretical training. This behavioral analysis can be supported with behavioral biometrics as every person has a unique way 
to express his/her self with individual behavioral characteristics such as body movement, coordination and usage [14]. Behavioral biometrics can reveal the psychology of the trainee when executing a task. VR and psychology have come closer with the commercial availability and accessibly of the technology [15]. The phycological analysis of maritime engines, and in general of any member of a vessel's crew is quite critical taking into consideration the operational conditions of a vessel.

Other technologies and scientific disciplines that have been studied and can be integrated in ShipSEVR over the time are computational intelligence for the identification of the training scoring process, affective neuroscience and learning, embodied agents, and emotional assessment using electroencephalography (EEG), for the emotional status recognition of the trainee. In our previous studies, we have cooperated with neuroscientists and developed a virtual reality evaluation toolkit for driving inspection [16]. The data gathered can be supported with machine learning and artificial intelligence for the optimization of the trainee's profile, the development of the appropriate training program to follow, and for the identification of his/her suitability on the execution of specific tasks.

Lastly, a technological area that has equal importance is the digital holography and the avatar technology. The two technologies can contribute significantly in the interactive training of the trainee and on the trainee's safety respectively. Holographic communication can transform the way feedback is given, how a subject is explained, and improve the way teaching, mentoring and coaching is delivered. Likewise, avatar technology can transform the VR experience by coordinating the avatar of a trainee on a critical and risky challenge is the digital engine room, avoiding physical exposure to risks.

\section{Conclusions}

Maritime training and education on safety issues has always been a prime concern for the industry. However, to maintain safety at the expected desired and requires standards it is important to reduce the seafarers' turnover. The increasing ship-to-shore mobility on the seafarers (officers and unlicensed mariners) requires attention and the retention of the experienced ones, taking into consideration the years spend at sea. Research indicates that retention issues in the shipping industry are related mostly with the employee and employer satisfaction on the job, the opportunities for career progression and the good working conditions [15].

ShipSEVR has been designed to address these issues by proving innovative workspaces that improve working conditions, increase job satisfaction, contribute to career development and retain the experienced seafarers. The concept behind the technology is not only the delivery of safety training on engine rooms and engines, but the execution of this delivery in pleasant, easy and rewarding way for all the parties involved. ShipSEVR revolutionizes the tools for safety training delivered by both the shipping company and the engine manufactures, offering developed opportunities to the seafarers to demonstrate their safety skills and career commitment. The commercialization of the technology has begun and will continue following the research progress. 


\section{Acknowledgments}

The authors would like to thank all five student teams, and staff members from Wärtsilä, Ade, and Turku University of Applied Sciences who have participated in the development of this training VR technology. This work was supported by Business Finland, several companies, and the Turku University of Applied Sciences.

\section{References}

1. Japan Transport Safety Board. https://www.mlit.go.jp/jtsb/statistics_mar.html

2. Maritime Injury Guide. https://www.maritimeinjuryguide.org/blog/top-reasons-maritimeaccidents/

3. Sampson H., Tang L.: Strange things happen at sea: training and new technology in a multibillion global industry, Journal of Education and Work, 29:8, 980-994. (2016)

4. Videotel. https://videotel.com/counting-the-costs-of-maritime-training/

5. Sanchez-Gonzalez P-L., Díaz-Gutiérrez D., Leo T., Núñez-Rivas L.: Toward Digitalization of Maritime Transport? MDPI Sensors , 19(4), 926; (2019)

6. Lukas U.: Virtual and augmented reality for the maritime sector - applications and requirements. In: IFAC Proceedings Volumes, Volume 43, Issue 20, pp. 196--200 (2010)

7. AR. Jeffrey.: Navigation Tools help prevent Collisions. Maritime Journal. (2019)

8. Nikitakos, N., Sirris, I., Dalaklis, D. et al.: Game-based learning for maritime education and training: the case of Trader of the World. WMU J Marit Affairs 16, pp. 265--291 (2017)

9. Cao F.: A Ship Driving Teaching System Based on Multi-level Virtual Reality Technology. International Journal of Emerging Technologies in Learning (iJET) - Volume 11, Issue 11, pp. 26--31 (2016)

10. Markopoulos E., Lauronen J., Luimula M., Letho P., Laukkanen S.: Virtual Training Technology in Maritime Safety. In: Proceedings of the 10th IEEE International Conference on Cognitive InfoCommunications, CogInfoCom, Volume. 1, pp. 283--288. October 23-25 2019. Naples, Italy (2019)

11. Microsoft. https://news.microsoft.com/apac/features/technology-and-the-sea-autonomousships-and-digital-captains/

12. Brookes, J., Warburton, M., Alghadier, M. et al.: Studying human behavior with virtual reality: The Unity Experiment Framework. Behav. Res. (2019)

13. Bhattacharya Y.: Employee Engagement as a Predictor of Seafarer Retention: A Study among Indian Officers. The Asian Journal of Shipping and Logistics. Volume. 31, Issue 2, pp. 295--318 (2015)

14. Pfeuffer K. J. Geiger M.J., Prange S., Mecke L., Buschek D.: Behavioral Biometrics in VR: Identifying People from Body Motion and Relations in Virtual Reality. In: Proceedings of the CHI '19: CHI Conference on Human Factors in Computing Systems. May 2019 Paper No. 110. Pp. 1--12 (2019)

15. Pan X. and Hamilton A. Why and how to use virtual reality to study human social interaction: The challenges of exploring a new research landscape. British Journal of Psychology, 109,pp. 395--417 (2018)

16. Luimula, M., Besz, A., Pitkäkangas, P., Suominen, T., Smed, J., Izullah, F.R., and Hämäläinen, H. Virtual Evaluation Tool in Driving Inspection and Training, In: Proceedings of the 5th IEEE Conference on Cognitive Infocommunications, Gyor, Hungary, pp. 57--60 (2015)

17. Caesar, L.D., Cahoon, S. \& Fei, J. : Exploring the range of retention issues for seafarers in global shipping: opportunities for further research. WMU J Marit Affairs 14, 141--157 (2015) 